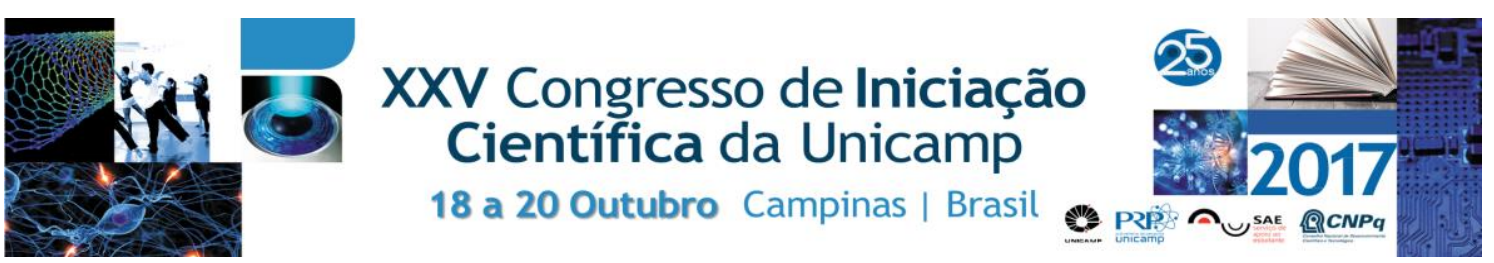

\title{
Encontrando o sexo apartir do viscerocrânio em uma coleção osteológica brasileira.
}

Lucas Del Vigna P. Peixoto*; Larissa Padovan, Graciele D. N. Silva, Maria Júlia A. Vicentin, , Viviane Ulbricht; Cristhiane Martins Schmidt; Eduardo Daruge Jr.; Francisco C. Groppo; Luiz Francesquini Júnior.

\begin{abstract}
Resumo
Objetivo: No presente estudo buscou-se verificar se algumas medidas do viscerocrânio são dimórficas e criar um modelo de regressão logística para a determinação do sexo. Metodologia: Estudo observacional analítico em 167 ossadas existentes no laboratório de antropologia física forense. Resultados: Verificou-se que todas as medidas realizadas são sexualmente dimórficas, exceção as medidas Frontozigomático direito - Zígio direito; Frontozigomático esquerdo - Zígio esquerdo. Foi possível criar um modelo de regressão logística [logito/Sexo $=-24.5+(0.20 \times$ Násio - Nasoespinha $)+(0.18$ $\times$ Zígio direito- Nasoespinha)] para determinar o sexo. Conclusão: Concluiu-se que o método quantitativo desenvolvido para determinação do sexo pelas medidas lineares faciais resulta em $81,4 \%$ de acerto.
\end{abstract}

\section{Palavras-chave: \\ Antropometria, Dimorfismo Sexual, Craniometria}

\section{Introdução}

A face é uma área muito importante do ser humano pois expressa a ancestralidade, o sexo, e a idade, dos indivíduos.Grande parte desta expressão se deve ao arcabouço ósseo, desenvolvido a partir da influência hormonal da adolescência (sexo somático), recebendo influência do meio ambiente e influência genética.

Nas mulheres este desenvolvimento ósseo finda aos 22 anos e nos homens aos 25 anos e o indivíduo do sexo feminino é em média $2 \%$ menor do que o indivíduo do sexo masculino.

Ressalta-se ainda que o crânio é em geral a parte do corpo mais encontrada, tanto em locais de crime, como também em locais de acidentes de massa ou grande, e juntamente com a pelve fornecem o resultado mais preciso para determinação do sexo.

O benefício de se ter um modelo de regressão logística para a área facial craniana que utiliza apenas duas medidas do viscerocrânio é o de se poder determinar o sexo de forma rápida e segura.

\section{Resultados e Discussão}

A avaliação dos testes revela que houve nítido efeito do sexo nas medidas, sendo que as medidas Frontozigomático (d)-frontozigomático(E), Zígio direito- Nasoespinha, Zígio esquerdo - Nasoespinha, Násio - Nasoespinha e Largura periforme máxima foram maiores nos homens. Entretanto, as medidas Frontozigomático direito - Zígio direito e Frontozigomático esquerdo - Zígio esquerdo não diferiram significativamente entre os sexos.

A regressão revelou que o modelo composto pelas medidas D (Zígio direito- Nasoespinha) e F (Násio - Nasoespinha) foi o melhor (Qui-quadrado=53.7, $p<0.0001$ ) para predizer o sexo. Assim o logito seria:

Sexo $=-24.5+(0.20 \times$ Násio - Nasoespinha $)+(0.18 \times$ Zígio direito- Nasoespinha) com um grau de acerto de $81,4 \%$. Após a análise estatística pode-se afirmar que todas as medidas realizadas são dimórficas. Somente duas medidas (frontozigomático direito - Zígio direito; Frontozigomático esquerdo - Zígio esquerdo) não se prestavam à determinação do sexo.

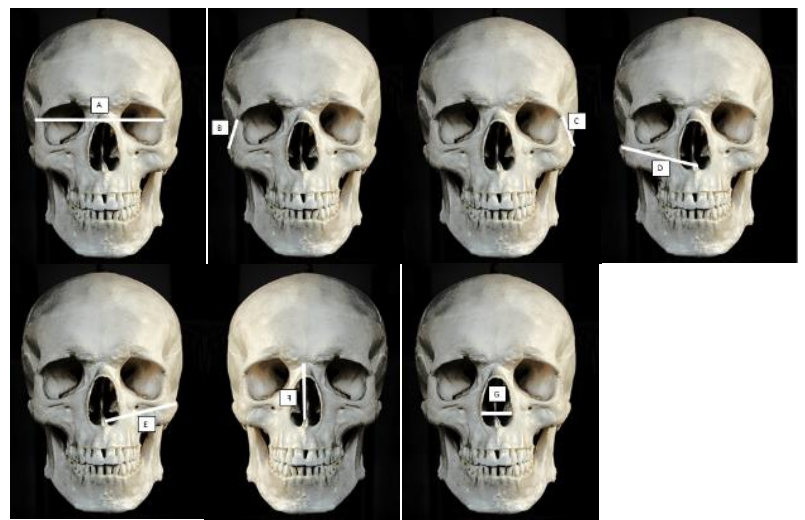

A - Frontozigomático direito-frontozigomático esquerdo, B Frontozigomático direito - Zígio direito, $\mathrm{C}$ Frontozigomático esquerdo - Zígio esquerdo, D - Zígio direito- Nasoespinhal, E - Zígio esquerdo - Nasoespinhal, F - Násio - Nasoespinhal, G - Largura periforme máxima

\section{Conclusão}

Verificou-se que as medidas realizadas são sexualmente dimórficas exceção das medidas Frontozigomático direito Zígio direito; Frontozigomático esquerdo - Zígio esquerdo, pois estas não são significativas para a determinação do sexo.

Foi possível criar um modelo de regressão logística para determinar o sexo [Logito/Sexo $=-24.5+(0.20 \times$ Násio Nasoespinha $)+(0.18 \times$ Zígio direito- Nasoespinha $)]$. O método quantitativo desenvolvido resulta em $81.4 \%$ de certeza.

\section{Agradecimentos}

Agradecimento a bolsa PIBIC/CNPq/SAE-PRP e a FOP/UNICAMP

\section{Referências Bibliográficas}

Arbenz GO. Medicina legal e antropologia forense. Rio de Janeiro Atheneu;1988. p.229-268.

Zaki ME, Soliman MA, El-Bassyouni HT. A cephalometric study of skulls from the bahriyah oasis. J Forensic Dent Sci. 2012 Jul [acesso 2016 mai 27]; 4(2):88-92, doi:10.4103/0975-1475. 109895. Disponível em https: www.ncbi.nlm.nih.gov/pme/articles/PMC 3669484/19146/pibic-2017-77962 